\title{
Category Features of Toast as Small Speech Genre
}

\author{
Nadezhda M. Loktionova, Svetlana A. Kruglova, Olesya A. Drozdova, Irina A. Zhyvotkova, and Olga Y. Potanina \\ Department of Foreign Languages, Don State Technical University, Academy of Civil Engineering and Architecture, Rostov-on- \\ Don, Russia
}

\begin{abstract}
Toasts logically fit into modern cultural space, including folklore. Folklore as a field of artistic creativity is widely spread in a variety of forms and types in modern reality. This phenomenon is dynamic, evolving, and quickly transformable; within humanitarian knowledge it interacts with such concise concepts as post-folklore, subculture; it reflects quality changes of public and everyday life of our era. Conceptually, the subject field of urban folklore is fairly well understood and even developed despite its specifics and complexity.
\end{abstract}

Toasts as a particular type of folklore creativity are placed in general semantic field of various genres of urban folklore along with congratulations, greetings, anecdotes, jokes, drinking songs, etc. The toast as a genre has existed for centuries century, and is being actively developed recently since it took a steady position as a key link of almost any feast (festive/unfestive). This is also caused by the general tendency in culture towards documentation of its 'messages'. The social demand for any printed materials as a logical reaction to changing reality (for example, various collections of toasts, jokes, anecdotal toasts, parables, festive scenarios; Internet products, etc.) promotes the widespread massive dissemination and functioning of folklore. Certainly, the standard printed goods 'made to order' devaluate and 'depersonalize' the material to some extent; but, on the other hand, they represent boundless opportunities for its variability, interpretation, reconsideration, and transformation, which in general corresponds to genre attributes of folklore.

Neologism texts of toasts confirm that a toast is not a usual text pronounced during a table ceremony. The toast shall be considered as a precedent text existing in two forms: oral and written, where the oral form takes the primary and main position, and the written one may be qualified as the secondary and conditional form since collections and websites contain various written demonstrations of toasts.

Separate objects of urban folklore still require more serious, careful, comprehensive consideration and linguistic description. This entirely refers to toasts, which until recently were not studied in domestic linguistics and cognitive science due some reasons, primarily extralinguistic. The authors believe that their close semantic interrelation and correlation to such concepts as 'feast' and 'binge' was one of the major obstacle to the study of toasts during the era of moral and ethical criteria. The derived shifts in people mindsets throughout the world regarding moral ethical standards, esthetic tastes towards their democratization, change of sociocultural values, popularity of group meals, and transformation of the 'culture of drinking' made it possible to include traditional folklore forms of folk art into a circle of artistic values.

With regard to genre and generic features toasts are rather diverse and closely interconnected with folklore 'subculture of leisure time', which conditionally and generally may be presented by two joined complexes of modern urban ceremonial folklore:

1) public life, including modern festivals, traditional thematic civil holidays, corporate parties, graduation parties, class reunions, initiation ceremonies (for example, students, soldiers, etc.) and many others;

2) domestic life, including weddings, birthday parties, anniversaries, baptism, bachelor parties, bachelorette parties, army farewell party, funeral and many others, which covers the repertoire of modern house feasts, including family celebrations.

At present, it is almost impossible to imagine all of the above-mentioned collective meals without toasts. This is the reason why toasts took a definite stand in the system of modern values related to culture and linguistics and is linguistically attractive for study as the genre of urban folklore.

According to many linguists, the name of this genre was borrowed from English: toast - through German toast or French toste, or directly from English toast derived from Latin panis tostus 'fried bread' because in England before making a speech the person was given a glass and a fried slice of bread [1]; toast - (English toast). Short after-dinner speech, toast. Originally in England the speaker was given a glass with water and a fried slice of bread [2]. People of the British Isles were very meticulous about this tradition and observed it for a long time: before drinking wine people dipped a fried

* Corresponding author: svetazh@inbox.ru 
slice of bread in a glass for a drink to absorb the grain flavor. Later, the tradition to dip bread into wine was forgotten, but there appeared another tradition to say a toast before drinking wine. Thus, the word 'toast' came to English lexicon in the $17^{\text {th }}$ century. In Russian lexicon it was recorded later, which is confirmed by history and etymology dictionary: "In Russian the word a toast is known from the first decades of the $19^{\text {th }}$ century. In dictionaries it is reflected since 1847" [3].

Another version of etymology of the word 'toast', which causes some disputes these days, deserves special attention. According to some philologists, the 'toast' derived from Turkic language. It is known from the Russian history, the word 'dostakan' (before drinking) occurs in the Russian writing in 1356 and in the Ivan Kalita's Spiritual Testament in 1340. It is anticipated that this word is a borrowing from the name of Turkic wooden ware - tostakan - low round ware similar to a bowl. It is supposed that the word toast comes from the word tostakan. The toast was given when the person was lifting a glass of drink, and it was TOSTakan, which was later called stakan (glass). Thus, both the glass (stakan) and the toast are integrated in one word tostakan. It should be mentioned that at present tostakan is widely used in Kazakhstan mainly for serving koumiss and represents the wooden ware resembling something between a drinking bowl and a soup bowl in shape. This version was not widely adopted; however, it has the right to exist since its justification is rather logical [4].

The analysis of existing and the most widespread definitions of a toast in special literature showed that despite general semantic components of such definitions, the linguistics still makes it unclear whether the toast refers to the act of speech or to the communicative act, or to a speech genre. The most relevant and acceptable is the concept by A. Vezhbitskaya, according to which it is advisable to link the concept of 'a speech genre' by $\mathrm{M}$. Bakhtin to the theory of speech acts. According to her, the word 'genre' confuses less than the word 'act' since 'act' is understood as a short and occasional statement [5]. According to V.V. Dementiev, this makes it possible to study the speech genre as "the system and structural phenomenon representing a complex set of various speech acts chosen and connected for reasons of a certain special purpose and relating to reality not directly but through a speech genre in general" [6].

Among all existing definitions of a toast the authors chose the definition proposed by Matveeva, which contains a critical semantic category feature, namely the emphasis is on the concept of a genre: "A toast is a small genre of household eloquence: after-dinner health speech, toast" [7].

Table speech genres form a special group of genres, which are regularly used in situations of a joint meal and being its indispensable attribute. "... Genres correspond to typical situations of speech communication, typical topics" [8]. According to M.M. Bakhtin, a language is used as certain single statements (oral and written) of participants in any field of human activity. These statements reflect specific conditions and purposes of each such field not only through the content (thematic) and language style, but first of all through the composite structure. "All these three aspects - thematic content, style and composite structure - are in general inseparably linked statements and are equally defined by the specifics of this field of communication. Undoubtedly, each separate statement is individual but each field of language use develops its relatively stable types of such statements called the speech genres" [8].

According to the authors, the toast is a special type of statement with particular set of features and stereotypic elements, a statement reflecting a certain area of human activity, namely the culture of a feast, the culture of a drink. It includes three obligatory components - topic, style and composition, which respectively have their specifics, i.e. are determined by the following factors: thematic content, structure and style (which components include lexical, phraseological, grammatical and other language means). Toasts are usually treated as the act of illocution, i.e. the act ensuring some intension. They imply a certain 'drama' of behavior of participants having certain communicative relations in a particular situation.

Besides integrated features typical for a toast as a primary speech genre, it also has some distinctive (differential) features. The first peculiarity is connected with the fact that toasts unambiguously belong to contactology aimed to express the most benevolent attitude towards the addressee, to establish positive contacts thus reducing a spatial distance between participants of a feast (unlike conflictology). A classical and traditional form of a toast in table ceremonies includes positive wishes and perorations.

The toasts reflect deep philosophical understanding of "the nature of a word" as a material feature leading to special concentrated life related, on the one hand, to antique ideas of spiritual entity of a word, to Christian teaching on Divine Logos; on the other hand, to philosophically intelligent metaphysics of a word (see for example, fundamental works by P.A. Florensky, S.N. Bulgakov, A.F. Losev, etc.). A word is similar to a living organism: it gets special power from a person due to which it is able to create its planetary space (V.S. Milovatsky).

Hence, main message of a toast: everything what is told about shall come true, materialize, and it implicates a certain special harmony of an informative part of a toast. It's not fortuitous that in many cultures (for example, Caucasian) toasts are positioned as peculiar 'charms' connected to word power, its creating force; 'charitable beginning' is always present since in order for the words to come true there is an appeal to the 'higher forces': "May God prosper you!', "Bless you!', "Let the Lord turn to you!", "Salve!”, etc.

According to T.V. Shmelyova's typology, the toast, first of all, is an etiquette and speech genre; its intention, creation, content, general rhetoric (semantic, pronouncing) correspond to all existing etiquette standards and ceremonial traditions. The communicative purpose of a toast is to emphasize the importance of any event, to express wishful thinking to the addressee. However, this concept to some extent narrows the volume of ritual speech genres. 
Following the ideas of O.S. Issers, the authors suppose that "only immediate and explicit purposes of communicants are considered while the hidden ones remain outside the linguistic analysis" [9]. In fact, the main communicative task is solved by consecutive achievement of some objectives, which remained beyond the study. Although in reality there is a huge variety of auxiliary objectives to achieve successful communication.

Thus, E.F. Tarasov points to the following auxiliary purposes: "Before you can speak with your interlocutor, you shall somehow draw his attention, come into contact with him. It is a critical part of communication: the success of a particular act of communication will depend on how the problem of drawing attention and establishing a contact will be solved" [10]. Directly after drawing the attention of the interlocutor other objectives preceding the message transmission can be achieved. For example, "the speaker may take efforts to create (maintain, destruct) the atmosphere of trust to a source of information and to the transferred data in order to provoke the interest in the transmitted message (to create informative demand)" [10]. These objectives are present in the speech genre of a toast and shall be considered.

From the point of view of speech etiquette, the toast performs the function of politeness, which "is a kind of contact function" [11]. One shall agree with the assumption of Kiselyova that "politeness//impoliteness" is the modification of a more generic category "rapport" [12]. The toast, as well as a congratulation, a gratitude, a compliment, an appeal, etc. is the expression of politeness and thus performs the contact function. It is assumed that the entire contextual background of a toast a priori implies the communicative strategy related to the category of politeness.

Within the aspect of speech etiquette another function of a toast is social and regulatory function, which content is defined by the dependence of the choice of a toast on the status and social roles of communicants, relations between them, place and situation as well as age, gender, national, racial and social identity, education, profession, marital status. It is known that these factors influence the choice of communicative behavior in an ambivalent manner: "First, being absolute characteristics of communicants, they define their language repertoire; secondly, being relative characteristics, they define the nature of relationship, constituting either symmetric or asymmetric systems of relations between communicants" [13]. Thus, for example, it will be inappropriate to say at a wedding a toast in honor of personal happiness of any guest; playful toasts will not suit an official event, and in a toast to the elderly person the address with a friendly 'you' and a wish of unbridled joy is not possible. Hence, the toast fulfills the function of social regulation determined by social roles of communicants, their social status, rules and norms of speech etiquette.

Despite the fact that almost every toast contains an epistle (traditionally prepared speech), epistolary cliches, speech formulas, they are accompanied by individual author's ideas since variability, various extent of improvisation, different transformations are typical for toasts. Thus, the toast genre possesses properties of both commonality and variability.

The toast as a certain communicative act belongs to the field of interpersonal relations and can be regarded as the act defining interactions of people: "The communicative act has conventional character. The convention is understood as the forms of interaction accepted in a society - including speech interaction" [14]. The definition of the communicative act implies the need of interaction between two parties - the 'transferring' and 'accepting' instances, i.e. the speaker and the addressee. Therefore, the toast is an act of interaction between the speaker and the addressee, i.e. the person delivering a speech and the person or a group of people to whom it is addressed.

The speaker assesses a speech situation, forms tasks of an action and choses language means: "The assessment by the speaker of hoe the speech will go further, there is "a dialogical layer" - focus on the addressee. Depending on addressee's expected or performed reaction in the course of a statement the above components of the speech action structure may be modified" [15].

N.D. Arutyunova fairly notes that "the speaker enters communication not as the global personality combining all components but as the "parametrized" personality revealing one of its social functions or psychological aspects according to which the statement is understood" [16]. Generally, the pronounced toast allows revealing widely different information about the speaker, for example, social function - a parent, a brother, a husband, a girlfriend, etc.; status -senior / younger family member, a colleague, a boss, etc.; psychological characteristics - mood, feelings, set of values, etc.

In the theory of speech genres, the position of the addressee comes to the forefront: "Each speech genre in every field of speech communication has its defining typical concept of the addressee" [8]. The toast, undoubtedly, is the addressed speech genre. "So far the unity of the focus on the addressee as one of the central 'components' in the structure of the communicative act has been achieved not due to the obvious reason that without the addressee the act of communication, exchange of information cannot take place, but due to the fact that both the speaker and the addressee to the same extent play a certain role in a speech situation" [14

Modern science recognizes that the addressee plays the most active role, which requires active actions. The 'presence' of the addressee is obvious. It is noteworthy that the addressee does not become an active player throughout the communicative act but acts as such at the beginning of interaction. "While speaking, I always consider the apperceptive aspect of my speech perception by the addressee, (...) all this will determine active reciprocal understanding of my statement by him" [8].

Following the ideas of S.A. Sukhikh, the authors consider that a personal aspect dominates in communication, and the structure of communicants in speech exchange shall be understood as "the structure of personalities including the identity features, character traits, abilities, which are organized definitely under the 
influence of temperament and mindset" [17]. The personal aspect by all means is present in toasts.

Any speech genre is aimed at a certain model of the addressee. Despite the fact that the speech is pronounced in honor of a certain person - the hero of the occasion, it is nevertheless heard by all people around the table. To characterize the roles of the audience G.G. Clark and T.B. Carlson introduce the concept of the 'audience sketch', according to which the audience is divided into the addressee and the participants of the speech act [18]. This is particularly important for such category of toasts as 'to all occasions' when the speech is devoted not directly to someone but to such abstract concepts as 'to love', 'to health', 'to happiness', 'to friendship', etc. In this case the addressee is the entire audience. The initiator of communication sets the purpose, and the addressee carries out the plan. Speech interaction in a toast is subordinated to the principles of goal-directed activity.

The authors believe that age psychological features of communicants really influence the process of communication and shall be considered as classification indicators. Moreover, certain achievements of gender linguistics at the present stage of linguistic development make it possible to believe that gender features of participants of communication shall also be considered within a communicative space since the identity of the communicant (addressee - speaker) undoubtedly has specific linguistic-psychological features.

The toast performs a phatic function. O.S. Akhmanova defines the phatic function function as one of the language functions, which, unlike communicative function, is demonstrated in situations, "in which the speaker does not strive to transmit a certain information to the addressee but wants to make a joint stay somewhere natural, to prepare the addressee to perceive the information, to attract attention, etc." [19].

The contact interaction directed to establish goodwill and leading to psychological rapprochement of interlocutors is implemented in a toast through appeals. Such appeals include: 'Dear guests!', 'Dear newlyweds!', 'Friends!' as well as the name of the addressee or some reference to him in the context of family relations (for example, 'Dear brother!', etc.).

G.G. Pocheptsov calls such speech actions 'a zero phase of communication' and adds: 'Often, the metacommunicative task solved at this stage of communication (besides establishing a speech contact) is defining an author / source of the message" [20]. The speech contact is made and the necessary parameters concerning the personality and mutual relations between communicants are specified through the phatic function in a toast.

Theoretical study of the conceptual nature of a toast demonstrates that the toast definitely belongs to etiquette-speech genres with all circumstances complying with existing ceremonial traditions, etiquette standards; in other words, the genre and etiquette reflection in toasts is obligatory. Besides, the study of toasts in the context of theoretical methodologically basic concepts related to communicative space showed that the linguistic nature of a toast demonstrates all components necessary for the communicative process and logically fits into a paradigm of speech communication according to a variety of parameters united by a topic and a situation of communication.

\section{References}

1. M. Fasmer, Etymological dictionary of Russian 4 (2003)

2. L.P. Krysin, Illustrative explanatory dictionary of foreign words (Eksmo, 2008)

3. P.Ya. Chernykh, Historical and etymological dictionary of modern Russian. 2 (1999)

4. http://encyclopaedia.bid/википедия/Тост

5. A. Vezhbitskaya, Speech genres $(99-111,1997)$

6. V.V. Dementiev, The study of speech genres: review of modern Russian philology 1 (1997)

7. T.V. Matveeva, Educational dictionary: Russian, culture of speech, stylistics, rhetoric (Flinta, Science, 2003)

8. M.M. Bakhtin, Esthetics of verbal creativity (1986).

9. O.S. Issers, Communicative strategy and tactics of the Russian speech (KomKniga, 2006)

10. E.F. Tarasov, Place of speech communication in a communicative act. National and cultural specifics of speech behavior. Editorial board: A.A. Leontyev, Yu.A. Sorokin, E.F. Tarasov $(67-96,1977)$

11. B.S. Zhumagulova, Collection of scientific works. 209, 16-30 (1983)

12. L.A. Kiselyova., Theory of speech influence (LSU, 1978)

13. L.M. Makarov, Procedural component of a speech situation. Speech acts in linguistics and methodology. Interuniversity collection of scientific works (Pyatigorsk, PSPIFL, 1986)

14. E.V. Klyuev, Speech communication (2002)

15. T.G. Vinokur, The speaker and the listener: Types of speech behavior (LGU, 2007)

16. N.D. Arutyunova, Language and the world. $2^{\text {nd }}$ edition, amended (Languages of the Russian culture, 1999)

17. S.A. Sukhikh, Struktura of communicants in communication (Kalinin, 1988)

18. G.G. Clark, T.B. Carlson, The listeners and the speech act (Progress, 1986)

19. O.S. Akhmanova, Dictionary of linguistic terms. $4^{\text {th }}$ edition (KomKniga, 2007).

20. G.G. Pocheptsov, Phatic metacommunication (Kalinin, 1981)

21. M.D. Vasilyeva, R.M. Vlasova, Yu.V. Nikolaeva, Yu.D. Potanina, VI International conference on cognitive science 1 (2015)

22. V.B. Gulida, Conference on National Linguistics: view of native speakers $\mathbf{5}$, (2013) 
23. I.G. Ovchinnikova, T.V. Akhutina, Language and thought: Modern cognitive linguistics 3 (2016)

24. S.D. Shelov, A.E. Tsumarev, IV International symposium on Terminology and knowledge $\mathbf{1 3}$ (2015) 